\title{
Crystal Structures and Magnetic Properties of the System $\mathbf{R h}_{1} \mathbf{M} \mathbf{n}_{1-x} \mathbf{S b}_{x}{ }^{*}$
}

\author{
By Hakaru Masumoto** and Kiyoshi Watanabe**
}

\begin{abstract}
Crystal structures and magnetic properties of $\mathrm{Rh}-\mathrm{Mn}$-Sb alloys have been investigated by means of Xray diffraction and magnetic measurements. It has been found that alloys in the composition range of $\mathrm{Rh}_{1.00} \mathrm{Mn}_{0.66} \mathrm{Sb}_{0.34} \sim \mathrm{Rh}_{1.00} \mathrm{Mn}_{0.55} \mathrm{Sb}_{0.45}$ are a solid solution of the face-centered tetragonal $\mathrm{L1}_{0}$-type with lattice parameters of $4.200 \sim 4.182 \AA$ and axial ratios of $0.806 \sim 0.829$. The typical $\mathrm{Rh}_{1.00} \mathrm{Mn}_{0.55} \mathrm{Sb}_{0.45}$ alloy has a saturation magnetization of $52.3 \mathrm{emu} / \mathrm{g}$ at absolute zero, a magnetic moment of $3.20 \mu_{\mathrm{B}}$ per $\mathrm{Mn}$ atom, a Curie point of $330^{\circ} \mathrm{K}$ and a paramagnetic Curie point of $286^{\circ} \mathrm{K}$. The observed relationship between reciprocal susceptibility and temperature indicates weak ferrimagnetic behavior of this alloy.
\end{abstract}

(Received May 23, 1975)

\section{Introduction}

Previous work on the crystal structures and magnetic properties of the intermetallic compounds in a series of $\mathrm{Rh}-\mathrm{Mn}-\mathrm{Sb}$ alloys ${ }^{(1)}$ has shown that $\mathrm{Cl}_{b}$-type compounds are formed near the composition $\mathrm{Rh}_{1} \mathrm{Mn}_{1} \mathrm{Sb}_{1}$, whereas at higher $\mathrm{Rh}$ concentrations the alloys indicate the $\mathrm{X}$-ray diffraction patterns indicative of the presence of a new crystal structure type in addition to the $\mathrm{Cl}_{b}$-type. $\mathrm{A}$ feature of interest also is the strong magnetization of these alloys.

The present work is concerned with the experimental results on alloys of the new crystal structure type.

\section{Experimental Procedure}

The alloy specimens were prepared from $99.99 \% \mathrm{Rh}$ and $\mathrm{Mn}$ and $\mathrm{Sb}$ of the same purities as reported previously ${ }^{(\mathbf{1})}$. Carefully weighed quantities of $\mathrm{Rh}, \mathrm{Mn}$ and $\mathrm{Sb}$ were sealed in evacuated silica tubes $6 \sim 7 \mathrm{~mm}$ in inner diameter and $50 \sim 70 \mathrm{~mm}$ long, melted at $1150 \sim$

* This paper was presented at the Autumn Meeting of the Japan Institute of Metals, October, 1971, Kanazawa, Japan. Published originally in Japanese in J. Japan Inst. Metals, 39 (1975), 1065. The 85th report from the Research Institute of Electric and Magnetic Alloys.

** The Research Institute of Electric and Magnetic Alloys, 2, Yagiyama-Minami, Sendai 982, Japan.

Trans. JIM $1350^{\circ} \mathrm{C}$ for $1 \mathrm{hr}$ in an electric furnace and then quenched in iced water. For the purpose of further homogenization, the alloys were pulverized, resealed in evacuated silica tubes and quenched in iced water again. The alloys thus obtained were examined by means of X-ray diffraction, and the above-mentioned operation was repeated until sufficient homogenization was realized. Finally, the alloys were prepared in the form of powder, bulk matter or rods, then homogenized at $700 \sim 1000^{\circ} \mathrm{C}$ for $40 \sim 100 \mathrm{hr}$ and cooled slowly at a rate of $100^{\circ} \mathrm{C} / \mathrm{hr}$.

The X-ray analysis of the crystal structures, and the lattice constant and magnetic measurements were entirely the same as described in a previous paper ${ }^{(1)}$.

\section{Results and Discussion}

\section{Crystal structure}

$\mathrm{X}$-ray diffraction studies on crystal structures of $\mathrm{Rh}-\mathrm{Mn}-\mathrm{Sb}$ alloys were performed using 29 alloys whose compositions are shown in Fig. 1. Figure 2 shows the diffraction patterns of the typical alloys $\mathrm{Rh}_{1.00} \mathrm{Mn}_{0.50} \mathrm{Sb}_{0.50}$ (No. 19), $\mathrm{Rh}_{1.00} \mathrm{Mn}_{0.55} \mathrm{Sb}_{0.45}$ (No. 18), $\mathrm{Rh}_{1.00} \mathrm{Mn}_{0.66}$ $\mathrm{Sb}_{0.34}$ (No. 13) and $\mathrm{Rh}_{1.00} \mathrm{Mn}_{0.70} \mathrm{Sb}_{0.30}$ (No. 11) which were held at $1000^{\circ} \mathrm{C}$ for $98 \mathrm{hr}$ and then slowly cooled. These alloys have compositions indicated by the open circles in the figure. Alloys No. 18 and No. 13 exhibit a single phase of the $f c t$ lattice type, while alloy No. 19 with a higher $\mathrm{Sb}$ concentration than alloy No. 18 shows the $f c t$ 


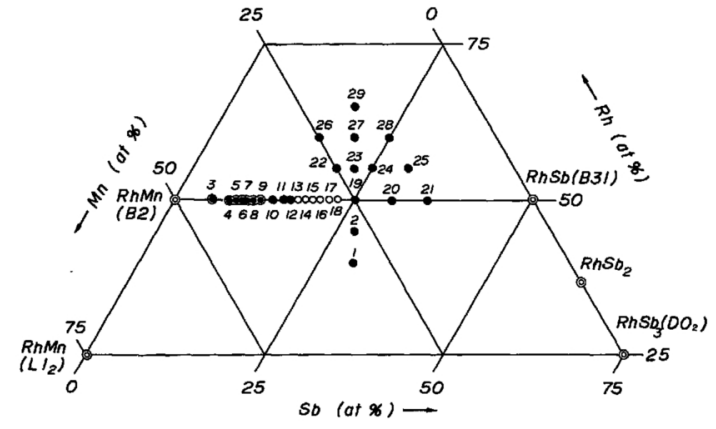

Fig. 1 Compositions of $\mathrm{Rh}-\mathrm{Mn}-\mathrm{Sb}$ alloys tested.

$\mathrm{O}: \mathrm{L} 1_{0}(\mathrm{CuAu})$-type

O:B2(CsCl)-type

:Two or three phases

phase together with a weak second phase corresponding to the $\mathrm{RhSb}$ compound ${ }^{(2)}$. This second phase cannot be removed by any heat treatment. Alloy No. 11 exhibits fairly strong diffraction lines of the B2-type that correspond to those of the RhMn compound ${ }^{(3) \sim(5)}$. Next, the

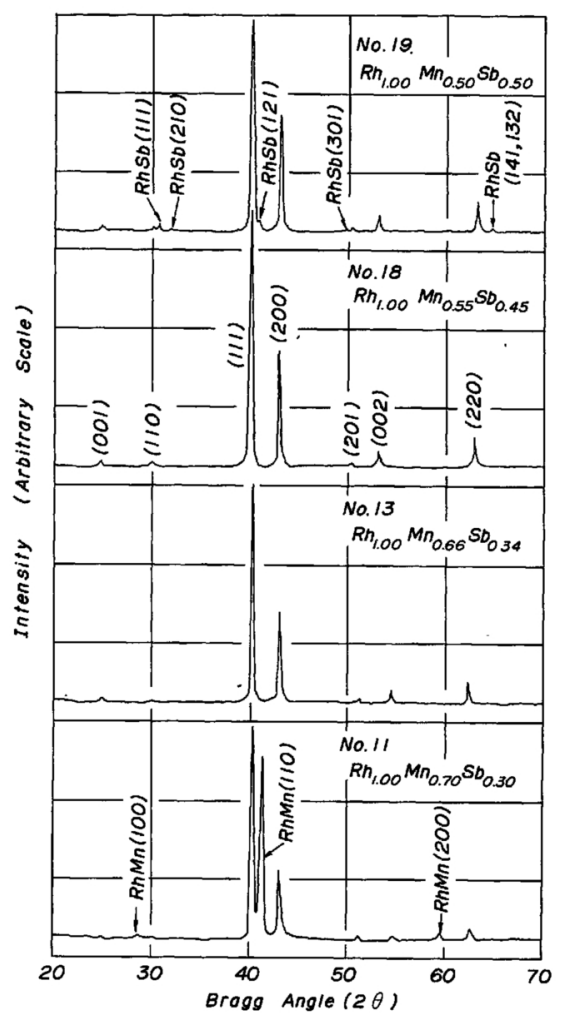

Fig. 2 X-ray diffraction pattern of $\mathrm{Rh}_{1} \mathbf{M n}_{1-x} \mathrm{Sb}_{x}$ alloy cooled at a rate of $50^{\circ} \mathrm{C} / \mathrm{hr} \mathrm{hr}$ after heating at $1000^{\circ} \mathrm{C}$ for $98 \mathrm{hr} \mathrm{Cu}-\mathrm{K} \alpha$ radiation.
Table 1 Comparison of observed and calculated data for X-ray $(\mathrm{Cu}-\mathrm{K} \alpha)$ diffraction lines of $\mathrm{Rh}_{1.00} \mathrm{Mn}_{0.55} \mathrm{Sb}_{0.45}$ alloy.

\begin{tabular}{|c|c|c|c|c|}
\hline \multirow{2}{*}{ Index } & \multicolumn{2}{|c|}{ Spacing $d(\AA)$} & \multicolumn{2}{|c|}{ Intensity } \\
\hline & Meas. & Calc. & Obs. & Calc. \\
\hline 001 & 3.466 & 3.467 & vw & 13 \\
\hline 110 & 2.956 & 2.957 & vw & 15 \\
\hline 111 & 2.253 & 2.250 & vs & 1815 \\
\hline 200 & 2.091 & 2.091 & $\mathrm{~s}$ & 745 \\
\hline 201 & 1.800 & 1.791 & vw & 8 \\
\hline 002 & 1.734 & 1.734 & $\mathrm{~m}$ & 205 \\
\hline 220 & 1.478 & 1.479 & $\mathrm{~m}$ & 237 \\
\hline 202 & 1.333 & 1.335 & $\mathrm{~m}$ & 336 \\
\hline 311 & 1.235 & 1.236 & s & 510 \\
\hline 222 & 1.127 & 1.125 & $\mathrm{~m}$ & 194 \\
\hline 400 & 1.045 & 1.046 & $\mathbf{w}$ & 83 \\
\hline 331 & 0.948 & 0.948 & $\mathrm{~m}$ & 154 \\
\hline 420 & 0.935 & 0.935 & $\mathrm{~m}$ & 155 \\
\hline
\end{tabular}

vs: very strong, s: strong, $\mathrm{m}$ : middle, w: weak and vw: very weak.

crystal structure in alloy No. 18 with the typical $f c t$ single phase has been analyzed. Table 1 shows a comparison between the calculated and experimental values of the interplanar spacing $d$ and the observed intensity of each diffraction line. There is excellent agreement between the calculated and observed values of the interplanar spacings. Assuming that the crystal structure of the alloy is of the fct $\mathrm{L} 1_{0}$ type (CuAu type) and that the $\mathrm{Rh}$ atom and the $\mathrm{Mn}$ and $\mathrm{Sb}$ atoms occupy the sites, $\left(000, \frac{1}{2} \frac{1}{2} 0\right)$ and $\left(0 \frac{1}{2} \frac{1}{2}, \frac{1}{2} 0 \frac{1}{2}\right)$, respectively, the crystal structure factor $\boldsymbol{F}$ of this alloy can be given as follows:

When $h+K$ is even with $\left\{\begin{array}{l}h=2 n \\ l=2 n\end{array}\right.$ and $\left\{\begin{array}{l}h=2 n+1 \\ l=2 n+1\end{array}\right.$, $\left.\boldsymbol{F}=2\left[f_{\mathrm{Rh}}+f_{(\mathrm{Mn}}+\mathrm{Sb}\right) / 2\right]$.

In the case of $\left\{\begin{array}{l}h=2 n \\ l=2 n+1\end{array}\right.$ and $\left\{\begin{array}{l}h=2 n+1 \\ l=2 n\end{array}\right.$,

$$
\boldsymbol{F}=2\left[\boldsymbol{f}_{\mathrm{Rh}}-\boldsymbol{f}_{(\mathrm{Mn}+\mathrm{Sb}) / 2}\right] \text {. }
$$

Here $f$ is the atomic scattering factor. The integral intensity of each diffraction line calculated from the $\boldsymbol{F}$, the results are in excellent agreement with the observed intensity. Therefore, the crystal structure of this alloy is determined to be of the fct $\mathrm{L1}_{0}$-lattice type as shown in Fig. 3 .

Figure 4 shows the lattice parameter for $\mathrm{Rh}_{1} \mathrm{Mn}_{1-x} \mathrm{Sb}_{x}$ alloys where $x$ is varied from 0.3 to 0.6 . As can be seen from the figure, the crystal 


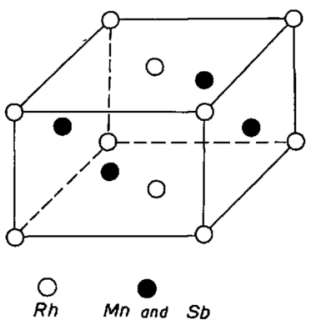

Fig. 3 Crystal structure of $\mathrm{L} 1_{0}$-type.

structures of alloys with $x=0.30 \sim 0.33$ show the coexistence of the two phases of the $\mathrm{L}_{0}$-and B2-types. The lattice parameter of the $\mathrm{L} 1_{0}$-type is $a=4.200 \AA$, which is nearly constant against composition. On the other hand, higher $\mathrm{Sb}$-concentration alloys with $x=0.50 \sim 0.60$ show the coexistence of the two phases of the $\mathrm{L} 1_{0}$ and B31-types, and the lattice parameter of $\mathrm{L} 1_{0}$-type is almost constant at $a=4.182 \AA$. The crystal structures of intermediate alloys with $x=0.34 \sim 0.45$ alloys out of the range of coexistence of the two phases are in the single phase state of the $\mathrm{L}_{0}$-type. The values of the lattice parameter $a$ in these alloys decreased linearly with increase in $x$, and both the lattice parameter $c$ and the atomic ratio $c / a$ increased appreciably with increase in $x$. The single-phase alloy No. 18 of the $\mathrm{L} 1_{0}$-type which is nearest to

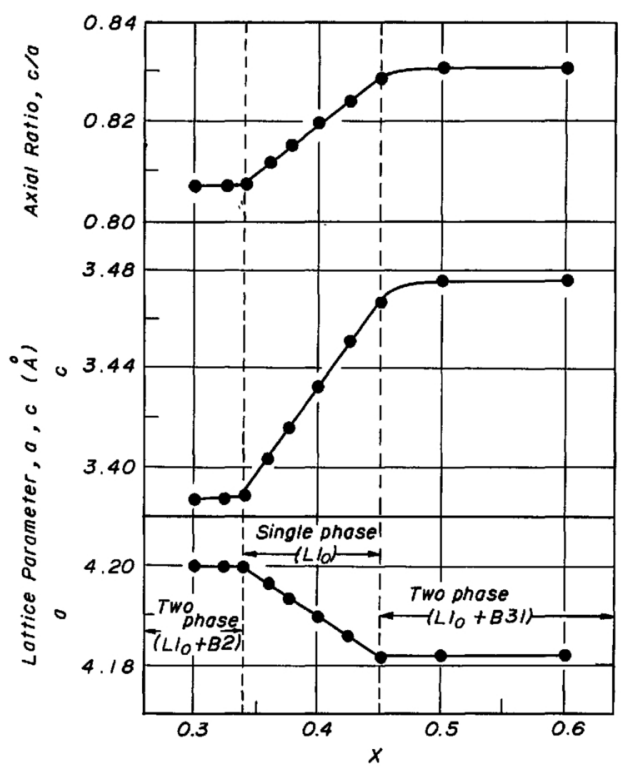

Fig. 4 Lattice parameters and axial ratios of $\mathrm{Rh}_{1} \mathrm{Mn}_{1-x}$ $\mathrm{Sb}_{x}$ alloys. the stoichiometric composition has $a=4.182 \AA$, $c=3.467 \AA$, and $a, c / a$ ratio of 0.829 .

Figure 1 shows the relation between the alloy phase and composition, where $\bigcirc$ indicates the single phase of the $\mathrm{L} 1_{0}$-type, the coexisting state of the $\mathrm{L}_{0}$-type with an additional crystal structure type phase, and 0 the single phase of the B2-type.

\section{Magnetic properties}

Figure 5 show the relation between the saturation magnetization $\sigma_{s}$ in a field of about

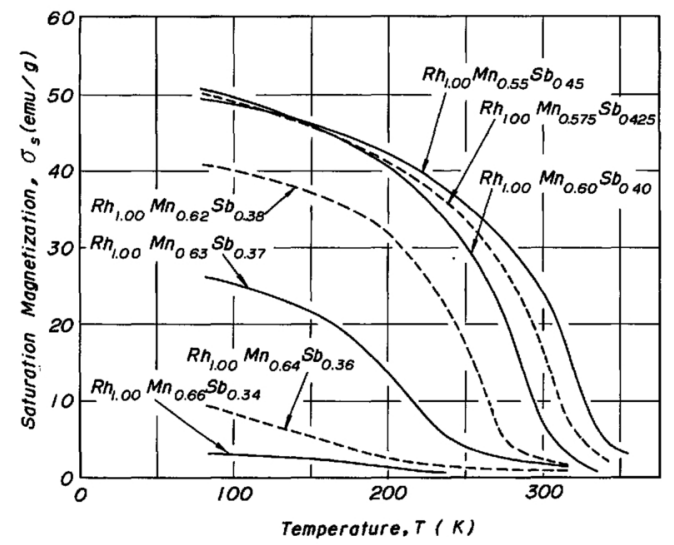

Fig. 5 Temperature dependence of saturation magnetization of $\mathrm{Rh}_{1} \mathrm{Mn}_{1-x} \mathrm{Sb}_{x}$ alloys cooled at a rate of $50^{\circ} \mathrm{C} / \mathrm{hr}$ after heating at $1000^{\circ} \mathrm{C}$ for $98 \mathrm{hr}$.

$10.6 \mathrm{kOe}$ and the temperature $T$ for seven $\mathrm{Rh}_{1} \mathrm{Mn}_{1-x} \mathrm{Sb}_{x}$ alloys with $x=0.34 \sim 0.45$ slowly cooled after a homogenizing treatment at $1000^{\circ} \mathrm{C}$ for $98 \mathrm{hr}$. The saturation magnetization of these alloys is a low as about $3 \mathrm{emu} / \mathrm{g}$ for the composition at $x=0.34$, whereas the value of $\sigma_{s}$ for the alloys with the compositions $x=0.36$ increases to about $10 \mathrm{emu} / \mathrm{g}$ at low temperature. Further, the alloy with the composition $x=0.37$ increases $\sigma_{s}$ up to about $27 \mathrm{emu} / \mathrm{g}$, and all the alloys with more than $x=0.40$ have constant $\sigma_{s}$ values of about $50 \mathrm{emu} / \mathrm{g}$ at low temperature. The Curie points $T_{c}$ in these alloys increase gradually with increase in $x$. The alloy with $x=0.45$ which is in the single phase of the $\mathrm{L}_{4}$-type and is nearest to the stoichiometric composition shows the highest temperature of $330^{\circ} \mathrm{K}$.

Figure 6 shows the composition dependence of the Curie point for the ten alloys containing those 


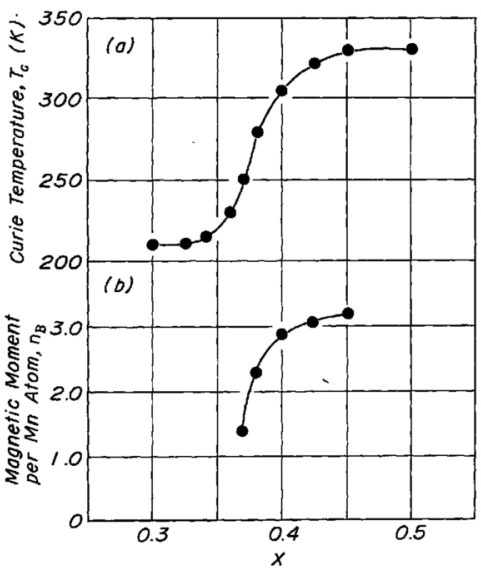

Fig. 6 Curie points and magnetic moments in $\mathrm{Rh}_{1} \mathrm{Mn}_{1-x} \mathrm{Sb}_{x}$ alloys.

in the two-phase state (a) and of the magnetic moment $n_{B}$ per $\mathrm{Mn}$ atom, obtained by extrapolating the saturation magnetization to $0^{\circ} \mathrm{K}$, for the alloys in the single phase of the $\mathrm{L}_{0}$-type (b). As regards the relation between the Curie points and composition in (a), the Curie points of the alloys with the compositions $x$ $=0.30$ and 0.33 are about $210^{\circ} \mathrm{K}$ and those of the alloys with $x=0.50$ and 0.45 have the temperature of $330^{\circ} \mathrm{K}$. Next, the magnetic moments of the alloys with $x=0.36$ are as low as $1.4 \mu_{B}$, but a large increase in a moment with increase in $\mathrm{Sb}$ concentration is observed indicating the highest value of $3.20 \mu_{B}$ in alloy No. 18 of the nearest stoichiometric composition. Since Mn and Sbatoms in alloy No. 18 of the $\mathrm{L} 1_{0^{-}}$ type are arranged in a disorder state at the sites $0 \frac{1}{2} \frac{1}{2}$ and $\frac{1}{2} 0 \frac{1}{2}$, the $\mathrm{Mn}-\mathrm{Mn}$ pair is considered to possess three different $\mathrm{Mn}-\mathrm{Mn}$ pairs $^{(6)}$ interatomic distances of $2.89,3.47$ and $4.18 \AA$ as shown in Fig. 7. However, according to the studies on ferromagnetic and antiferromagnetic Mn base compounds, flourite-type compounds or Heusler-type compounds, the interatomic distances of these ferromagnetic and antiferromagnetic $\mathrm{Mn}-\mathrm{Mn}$ pairs are experimentally assigned generally to be of the order of 2.89 and $4.18 \AA$. Consequently, if the two kinds of the $\mathrm{Mn}-\mathrm{Mn}$ pairs in the alloys of the $\mathrm{LI}_{0}$-type have different magnetic moments and the directions of the spins in the $\mathrm{Mn}$ atom are antiparallel to each other, the alloys exhibit

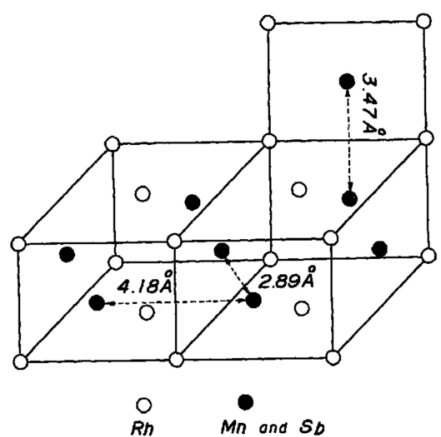

Fig. 7 Distances of pair of $\mathrm{Mn}-\mathrm{Mn}$ in $\mathrm{L}_{1}$-type alloy $\mathrm{Rh}_{1.00} \mathrm{Mn}_{0.55} \mathrm{Sb}_{0.45}$.

ferrimagnetic properties. Further, if one of the two $\mathrm{Mn}-\mathrm{Mn}$ pairs is non-magnetic, these alloys appear to have ferromagnetic properties due to the spin of another pair.

In Fig. 8 is shown the relation between the magnetic susceptibility $\chi_{g}$ and the reciprocal susceptibility $1 / \chi_{g}$ above the Curie temperature, and temperature for alloy No. 18 which is a representative fct alloy in the system $\mathrm{Rh}_{1}$ $\mathrm{Mn}_{1-x} \mathrm{Sb}_{x}$. As can be seen from the figure, the values of $1 / \chi_{g}$ between 550 and $800^{\circ} \mathrm{C}$ are varied linearly with temperature obeying a Curie-Weiss law, but at lower temperatures it decreases along the concave curve against transverse axis with decreasing temperature. Therefore, the paramagnetic Curie point $\theta_{p}$ of this alloy show

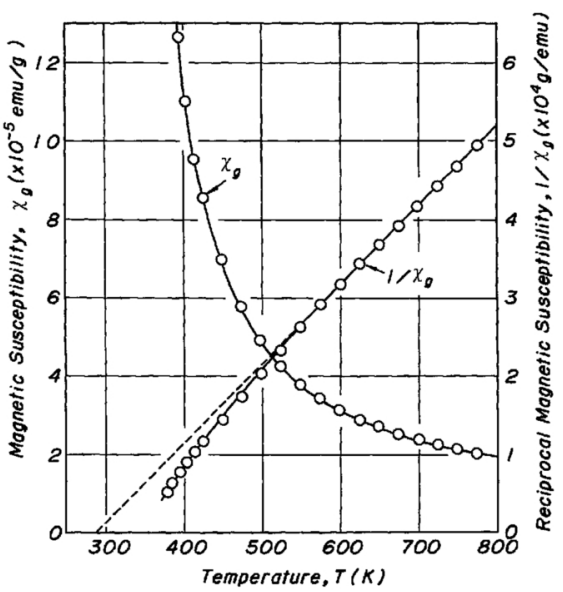

Fig. 8 Temperature dependence of magnetic susceptibility and reciprocal magnetic susceptibility of the alloy $\mathrm{Rh}_{1.00} \mathrm{Mn}_{0.55} \mathrm{Sb}_{0.45}$. 
the low $286 \pm 3^{\circ} \mathrm{K}$, rather than the Curie point $T_{c}$ $=330^{\circ} \mathrm{K}$. This result shows that this alloy may have some ferrimagnetic properties.

\section{Conclusions}

X-ray diffraction and magnetic measurements have been performed on $29 \mathrm{Rh}-\mathrm{Mn}-\mathrm{Sb}$ ternary alloys after sufficient homogenizing treatment at high temperatures. The obtained results are summarized as follows.

(1) The $\mathrm{Rh}_{1.00} \mathrm{Mn}_{0.55} \mathrm{Sb}_{0.45}$ alloy have the crystal structure of the gace-centered tetragonal $\mathrm{L1}_{0}$-type, in which the $\mathrm{Rh}$ sites are $\left(000, \frac{1}{2} \frac{1}{2} 0\right)$ and the $\mathrm{Mn}$ and $\mathrm{Sb}$ sites are $\left(0 \frac{1}{2} \frac{1}{2}, \frac{1}{2} 0 \frac{1}{2}\right)$. This alloy has a lattice parameter of $4.182 \AA$, its axial ratio $c / a$ being 0.829 .

(2) The lattice parameters of $\mathrm{Rh}_{1} \mathrm{Mn}_{1-x} \mathrm{Sb}_{x}$ with $x=0.34$ to $x=0.45$ in the single phase of the solid solution of the $\mathrm{L}_{0}$-type range from 4.200 to $4.182 \AA$. In the lower composition region $\mu_{B} x=0.34$ the alloys show the coexistence of the two phases of the $\mathrm{L1}_{0}$-type and the B2-type (RhMn), whereas in the higher composition region than $x=0.45$ the alloys show the coexistence of the two phases of the $\mathrm{L} 11_{0}$-type and B31-type (RhSb).

(3) The saturation magnetic moment per $\mathrm{Mn}$ atom and the Curie point of the $\mathrm{Rh}_{1.00} \mathrm{Mn}_{0.55} \mathrm{Sb}_{0.45}$ alloy are found to be $3.2 \mu_{\boldsymbol{B}}$ and $330^{\circ} \mathrm{K}$, respectively, this alloy has been assumed to have some ferrimagnetic properties from the relation between $1 / \chi_{g}$ and temperature.

\section{Acknowledgment}

The authors wish to thank Mr.Y.Kobayashi, a technical staff at our Institute, for his cooperation in making the alloys.

\section{REFERENCES}

(1) H. Masumoto and K. Watanabe : J. Japan Inst. Metals, 36 (1972), 680; Trans. JIM, 14 (1973), 177.

(2) H. Peisterer and K. Schubert:Z. Metallk., 41(1950), 358; Naturwiss., 37 (1950), 112.

(3) E. Raub und W. Mahler: Z. Metallk., 46 (1955), 282.

(4) J. S. Kouvel, C. C. Hartelius and L. M. Osika: J. Appl. Phys., 34 (1963), 1095.

(5) A. Kußmann, K. Müller und H. Wollenberger : Z. angew. Phys., 20 (1966), 461.

(6) M. Asanuma: Metal Phys. (Japanese), 7 (1961), 3. 